\title{
Investigation and Comparison of SCFRC Properties Incorporating Fly Ash and Zeolitic Additives
}

\section{Paulius Grigaliūnas*, Žymantas Rudžionis}

Kaunas University of Technology, Faculty of Civil Engineering and Architecture

Studentu st. 48, LT-51367 Kaunas, Lithuania

*Corresponding author: paulius.grigaliunas@ktu.lt

$\Gamma$

crossef http://dx.doi.org/10.5755/j01.sace.9.4.7482

Various properties of self-compacting concrete (SCC) and fresh mixture attracts the researchers and civil engineers' interest. It has been achieved a lot since its first introduction in 1980 in Japan. SCC virtually replaced the conventional vibrated concrete, and in many countries it started developing the SCC culture of construction technology. Currently, researchers are actively searching for new local secondary raw materials to be used as micro fillers. SCC mechanical and technological properties are being improved by incorporating partially oriented dispersive reinforcement.

In this paper, influence of two waste materials: fly ash and synthetic zeolite, obtained from oil cracking process - on self-compacting fiber reinforced concrete (SCFRC) rheology and mechanical properties are compared while cement is partly replaced (10-30\%) by those waste materials. Possibility of replacing the fly ash additive, which is quite widely used in the region, by zeolitic waste, obtained from oil cracking process, is analysed in this paper. Slump flow, $\mathrm{t}_{500}$ slump flow duration, J-ring tests are analysed. In addition, results of cement paste and hardened cement paste comparative research, X-ray analysis, shrinkage strain and mechanical properties are presented.

Studies show that selected additives classified as secondary raw materials have the capacity of modifying mixture plastic viscosity and yield stress values which are extremely significant properties for concrete workability in heavy reinforced structures, as well as for fiber orientation factor.

KEYWORDS: spent catalytic cracking, fly ash, rheology, self-compacting concrete.

Self-compacting, high performance or high workability concrete contains large amounts of cement and chemical additives which are closely linked to economical, technical, and environmental issues. Incorporation of large cement content can be characterized by disadvantages, including high hydration heat and high autogenous shrinkage. In most cases, cement is being replaced by various inert or pozzolanic materials such as silica fume. A very common mineral admixture is fly ash which is readily available in the countries having coal combustion plants. It is necessary to find less expensive locally available alternative mineral admixtures, e.g. natural or synthetic zeolite.

\section{Pozzolanic activity}

Large quantities of reactive $\mathrm{SiO}_{2}$ and $\mathrm{Al}_{2} \mathrm{O}_{3}$ in natural or synthetic zeolite which reacts with $\mathrm{Ca}(\mathrm{OH})_{2}$ to form further calcium silicate and calcium aluminosilicate are responsible for pozzolanic activity of this mineral admixture (Sabet et al. 2013, Poon et al. 1999, Pacewska et al. 2002, Caputo et al.

\section{Introduction}

Investigation and Comparison of SCFRC Properties Incorporating Fly Ash and Zeolitic Additives

Received 2014/07/01

Accepted after revision 2014/11/25

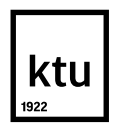

Journal of Sustainable Architecture and Civil Engineering Vol. 4 / No. 9 / 2014 pp. $35-49$ 
2008). Spent catalytic cracking catalyst used in oil refineries all around the world also demonstrates clear pozzolanic activity in Portland hardened cement paste (Pacewska et al. 2013, Bukowska et al. 2004, Payá et al. 2009), Payá et al. 2001, Glasser et al. 2011, Chen et al. 2004, Wu et al. 2003). Many scientists indicate similar characteristics of natural zeolites, including the following: large specific surface area, porous surface structure, pozzolanic activity within hardened cement paste, higher water demand in paste of normal consistency (WD) compared to cement, etc. Therefore, it should be noted that natural or spent catalytic cracking catalysts, derived from different sources, are defined by different physical characteristics and of different mineralogical composition. These factors affect the pozzolanic activity and behaviour in cement paste or in concrete. The following advantages could be attributed to zeolitic waste in the context of production: environmental dimension (lower cement consumption, reduced energy consumption, reduction of carbon dioxide emissions), economical dimension (in some cases, the price of zeolitic waste is relatively lower than of cement), technological advantages (improved properties of concrete mixture and hardened concrete, as well as of the paste). During the technological oil refinery process at oil treatment plants (fluid catalytic cracking process or FCC), different impurities, including heavy metals, tend to contaminate the zeolites, therefore, in order to use them in construction materials, different issues may arise related to hazards, technological factors, etc. In terms of hazards, it is the most advisable to use it in construction materials intended for industrial purposes (Aleknevičius 2008). When analysing the XRD patterns and DSC curves of hydrated cement pastes with different FCC contents, a significant decrease of the amount of portlandite $\mathrm{Ca}(\mathrm{OH}) 2$ was observed (Wu et al. 2003). Results proved that, similarly to other cases when using other active pozzolanic additives, more $\mathrm{CSH}$ gel and $\mathrm{Aft}$, but less $\mathrm{Ca}(\mathrm{OH})_{2}$ is produced for pastes with greater amount of FCC.

\section{Rheological properties}

One of the key factors influencing the workability and self-compatibility is the rheological properties of the concrete mixture. Research literature suggests that when increasing the amount of steel fiber in the SCC mixture, the slump flow of the mixture decreases, and the viscosity of the mixture increases (Prisco et al. 2011, Ponikiewski 2010).

The physical interactions may be called as increasing the specific surface area of the binder, and the changes in grading of solid materials of the concrete that in turn affects packing density of concrete particles. The above effects contribute to changes in the properties of high performance self-compacting concrete, especially in its rheological properties, which may have some effects on the properties of hardened concrete (Sabet et al. 2013). Studies show that the partial replacement of cement by fly ash can change the rheology properties of SCC mixtures (Dinakar et al. 2013). Researchers point out that a small slump flow increases, compared to the control composition that was recorded in the case where as much as $50 \%$ of cement was replaced by fly ash. $70 \%$ replacement causes sudden decrease in slump flow, however, by changing slump flow, the slump flow time ratio $t_{500}$ did not show significant variation. Incorporating fly ash in the mixtures reduces the amount of superplasticizer needed for reaching the target slump flow. The superplasticizer dosage in the mixtures containing fly ash was by $0.2 \%$ and $0.5 \%$ less than in control mixture (Sabet et al. 2013). The reason may be attributed to the spherical geometry of fly ash particles which easily roll over one another and also can disperse agglomeration of cement particles. The spherical shapes reduce the friction at the aggregate-paste interface which produce a "ball-bearing effect" at the point of contact (Sabet et al. 2013). Researchers describe compounds with relatively high $\mathrm{t}_{500}$ ratio such as 5-7 s. (Dinakar et al. 2013). Even so, the slump flow still reaches $620-700 \mathrm{~mm}$.

The superplasticizer (SP) dosages in the mixtures containing natural zeolite are higher than that in the control mixture. The higher the replacement of cement by natural zeolite, the more of SP is required to achieve the target slump flow (Sabet et al. 2013, Najimi et al. 2012, Ranjbar et al. 2013, 
Ahmadi et al. 2010, Su et al. 2000). This is probably due to the large amount of pores in the frame structure and high surface area of natural zeolite which in turn increases the quantity of water adsorbed on the particle (Najimi et al. 2012, Ranjbar et al. 2013, Şahmaran et al. 2008). However, research carried out by other researchers show that the replacement of cement by zeolite at $5-15 \%$ did not affect the workability of concrete, although it slightly increased the viscosity of fresh concrete (Chan et al. 1999). Literature overview revealed that t500 flow and V-funnel time generally increases with the increase of natural zeolite content. In most cases, this is again explained by higher surface area and larger paste volume of the mixtures (Ranjbar et al. 2013). SEM micrographs of the FCC from oil refinery plants shows totally different shaping (see Fig. 4), while chemical compositions stay similar to natural zeolite.

\section{Compressive strength}

Integration of pozzolanic materials has an important influence on concrete compressive strength, depending on its type, content, and properties. On the other hand, combination of pozzolanic materials with Portland cement increases the strength of concrete more, compared to the usage of slag cement (Abd Elrahman el al. 2014). In terms of compressive strength, it is stated that it is worth using fly ash for replacing up to $30 \%$ in some cases (Dinakar el al. 2013). Other researchers also indicate that replacing cement by $10 \%$ and $20 \%$ of fly ash raised the 28 -day compressive strength (Sabet el al. 2013, Chan el al. 1999, Karakurt el al. 2011). Increase in compressive strength of the mixtures containing fly ash could be explained by the fact that the voids between cement grains are filled with smaller particles of fly ash and also by pozzolanic reactivity (Sabet el al. 2013). Mechanical properties also depend on the type of used fly ash. Higher values were present when using material of finer composition (Abd Elrahman el al. 2014).

Natural zeolite at the replacement level of $10 \%$ improves the compressive strength of the control mixture, yet replacement $20 \%$ of cement by natural zeolite caused reduction in compressive strength at all terms, and that could be related to the higher void content in this concrete, compared to other mixtures (Sabet el al. 2013, Chan el al. 1999, Ranjbar el al. 2013, Ahmadi el al. 2010). In some cases, replacement rate of $10-20 \%$ shows higher compressive strength (Karakurt el al. 2011, Bilim 2011). It was found by X-ray diffraction (XRD) analysis that replacement of $10 \%$ of cement by zeolite reduced the amount of $\mathrm{Ca}(\mathrm{OH})_{2}$ (Chan el al. 1999). M.M. Ranjbar el al. (2013) indicated that natural zeolite in SCC shows better performance in a lower W/B ratio. However Poon el al. (1999) reports that cement replacement by zeolite did not increase the 28,90 or 180 day compressive strength of the blended paste at replacement level of $10 \%$, similarly to many other investigations.

Increase of compressive strength is influenced not only by pozzolanic properties of FCC. Increase in strength in mortars appears to be more significant than that in pastes, as the former was observed to have higher rate of strength gain than the latter. It is ascertained that pozzolanic materials also act as micro fillers, and they improve the interface and as a result of this, the strength increases. Researchers (Wu el al. 2003) present SEM micrographs of mortars (W/B = 0.3) cured for 7 days and containing $0 \%$ and $15 \%$ of FCC. The mortar with no waste catalyst appears to be more porous and there is a separation between cement paste and aggregate. The presence of zeolitic waste results in improved binding between cement paste and sand.

\section{Drying shrinkage}

According to Najimi el al. (2012), the application of natural zeolite led to a considerable decrease in drying shrinkage at dry conditions. The drying shrinkage of mixtures with $15 \%$ and $30 \%$ of replaced cement were about $84 \%$ and $64 \%$ of that of the control concrete after 90 days, respectively. It is noted that internal the curing ability of natural zeolite is similar to that of lightweight concrete. It 
means that natural zeolite as a porous material absorbs a part of water in fresh state of concrete, and this water gradually migrates out of natural zeolite during drying of hardened concrete.

\section{Summary}

It is generally accepted that $10 \%$ of zeolite in SCC can be considered as a suitable replacement regarding the economic efficiency, fresh and hardened properties of natural zeolite supplemented concrete (Ranjbar el al. 2013). Meanwhile, it is stated and recommended that the best properties of SCC can be achieved with fly ash replacement of cement by $30-50 \%$.

To sum up, the role of fine fly ash in reducing the porosity and enhancing the concrete durability can be basically interpreted in several aspects: (Abd Elrahman el al. 2014), packing density, pozzolanic activity, enhanced cohesion and reduced amount of free water, densified transition zone, reduced water demand, lower hydration heat and thermal stress. Moreover, some mineral admixtures like natural or synthetic zeolites could eliminate the need for viscosity modifying agents (VMA) and improve properties of concrete in fresh and hardened state.

\section{Methods}

The general aim was to identify and compare technological and mechanical properties of SCC mixtures when part of the cement in the mixture was replaced by zeolitic waste, fly ash, and

Table 1

SCC mixture compositions in the investigation of technological properties

\begin{tabular}{|c|c|c|c|c|c|c|c|c|c|c|}
\hline Group & $\begin{array}{l}\text { Mix } \\
\text { No. }\end{array}$ & $\begin{array}{l}\text { Cement, } \\
\mathrm{kg} / \mathrm{m}^{3}\end{array}$ & $\begin{array}{l}\text { Water, } \\
\mathrm{kg} / \mathrm{m}^{3}\end{array}$ & $\begin{array}{c}\text { Sand } \\
0 / 2 \text {, } \\
\mathrm{kg} / \mathrm{m}^{3}\end{array}$ & $\begin{array}{c}\text { Sand } \\
0 / 4 \text {, } \\
\mathrm{kg} / \mathrm{m}^{3}\end{array}$ & $\begin{array}{c}\text { Coarse } \\
\text { aggregate } \\
4 / 16 \\
\mathrm{~kg} / \mathrm{m}^{3}\end{array}$ & $\begin{array}{c}\text { Steel } \\
\text { fiber, } \\
\mathrm{kg} / \mathrm{m}^{3}\end{array}$ & $\begin{array}{l}\text { Zeolite } \\
\%^{*}\end{array}$ & $\begin{array}{l}\text { Fly } \\
\text { ash, } \\
\% \text { * }\end{array}$ & $\begin{array}{l}\text { VMA } \\
* * \star\end{array}$ \\
\hline \multirow{4}{*}{$\begin{array}{l}\text { Mix A including } \\
\text { different } \\
\text { amounts of steel } \\
\text { fiber ** }\end{array}$} & 1 & \multirow{4}{*}{410} & \multirow{4}{*}{225,0} & \multirow{4}{*}{133,1} & \multirow{4}{*}{893,9} & \multirow{4}{*}{859,9} & 0 & \multirow{4}{*}{0} & \multirow{4}{*}{0} & \multirow{16}{*}{$\begin{array}{c}4,10 \\
(1,0 \%)\end{array}$} \\
\hline & 2 & & & & & & 15 & & & \\
\hline & 3 & & & & & & 25 & & & \\
\hline & 4 & & & & & & 35 & & & \\
\hline \multirow{3}{*}{$\begin{array}{l}\text { Mix B including } \\
\text { different } \\
\text { amounts of } \\
\text { zeolite. Steel } \\
\text { fiber } 0 \mathrm{~kg} / \mathrm{m}^{3 * *}\end{array}$} & 5 & 369 & \multirow{3}{*}{225,0} & \multirow{3}{*}{133,1} & \multirow{3}{*}{893,9} & \multirow{3}{*}{859,9} & \multirow{3}{*}{0} & 10 & 0 & \\
\hline & 6 & 328 & & & & & & 20 & 0 & \\
\hline & 7 & 287 & & & & & & 30 & 0 & \\
\hline \multirow{3}{*}{$\begin{array}{l}\text { Mix C including } \\
\text { different } \\
\text { amounts of } \\
\text { zeolite. Steel } \\
\text { fiber } 25 \mathrm{~kg} / \mathrm{m}^{3 * *}\end{array}$} & 8 & 369 & \multirow{3}{*}{225,0} & \multirow{3}{*}{133,1} & \multirow{3}{*}{893,9} & \multirow{3}{*}{859,9} & \multirow{3}{*}{25} & 10 & 0 & \\
\hline & 9 & 328 & & & & & & 20 & 0 & \\
\hline & 10 & 287 & & & & & & 30 & 0 & \\
\hline \multirow{3}{*}{$\begin{array}{l}\text { Mix D including } \\
\text { different } \\
\text { amounts of fly } \\
\text { ash. Steel fiber } \\
0 \mathrm{~kg} / \mathrm{m}^{3 *}\end{array}$} & 11 & 369 & \multirow{3}{*}{225,0} & \multirow{3}{*}{133,1} & \multirow{3}{*}{893,9} & \multirow{3}{*}{859,9} & \multirow{3}{*}{0} & 0 & 10 & \\
\hline & 12 & 328 & & & & & & 0 & 20 & \\
\hline & 13 & 287 & & & & & & 0 & 30 & \\
\hline \multirow{3}{*}{$\begin{array}{l}\text { Mix F including } \\
\text { different } \\
\text { amounts of fly } \\
\text { ash. Steel fiber } \\
25 \mathrm{~kg} / \mathrm{m}^{3 * *}\end{array}$} & 14 & 369 & \multirow[b]{3}{*}{225,0} & \multirow[b]{3}{*}{133,1} & \multirow[b]{3}{*}{893,9} & \multirow[b]{3}{*}{859,9} & \multirow[b]{3}{*}{25} & 0 & 10 & \\
\hline & 15 & 328 & & & & & & 0 & 20 & \\
\hline & 16 & 287 & & & & & & 0 & 30 & \\
\hline
\end{tabular}

Note * The indicated percentage of cement replaced by zeolitic waste and fly ash, i.e. 10, 20, 30\%.

** Properties of each mix have been investigated twice: once with $2.0 \%$ of added superplasticizer ("Sika" ViscoCrete-D187), and the second - 2.5\%.

*** "Sika” Stabilizer 4R. 
incorporated with steel fiber. Also, to compare the spent zeolitic catalytic cracking catalyst with respect to another artificial pozzolanic material - fly ash which in general is of similar chemical composition and high pozzolanic activity. The experimental programme involves two major parts: investigation of cement paste and hardened cement paste, as well as investigation of fresh concrete mixture and concrete. Mechanical properties of hardened cement paste were identified in the research when $\mathrm{W} / \mathrm{B}=\mathrm{WD}$ and $\mathrm{W} /$ $\mathrm{B}=$ const. In order to investigate the effect of zeolitic waste and fly ash and its proportion on various rheological and mechanical properties of grouts, 16 concrete mixtures at a constant W/B (water/ binder) of 0.55 were designed and attributed to different groups from A to F. Water, aggregates, and VMA (viscosity modifying agent) content remained constant at all mixes. In mix $A$, only the content of steel fiber varies. In mix $B$, only replacement level of zeolite varies while no steel fiber is used. In mix C, level of replacement by zeolite varies while content of steel fiber stays constant at $25 \mathrm{~kg} / \mathrm{m}^{3}$. Mixes $D$ and $F$ replicates $B$ and $C$, only changing the additive zeolite to fly ash (see Table 1). Rheological properties of each mix were determined twice: with 2.0 and $2.5 \%$ of superplasticizer. "Sika ViscoCrete" - D187 high range superplasticizer and "Sika Stabilizer 4R" VMA were used to improve workability properties of SCC mixes.
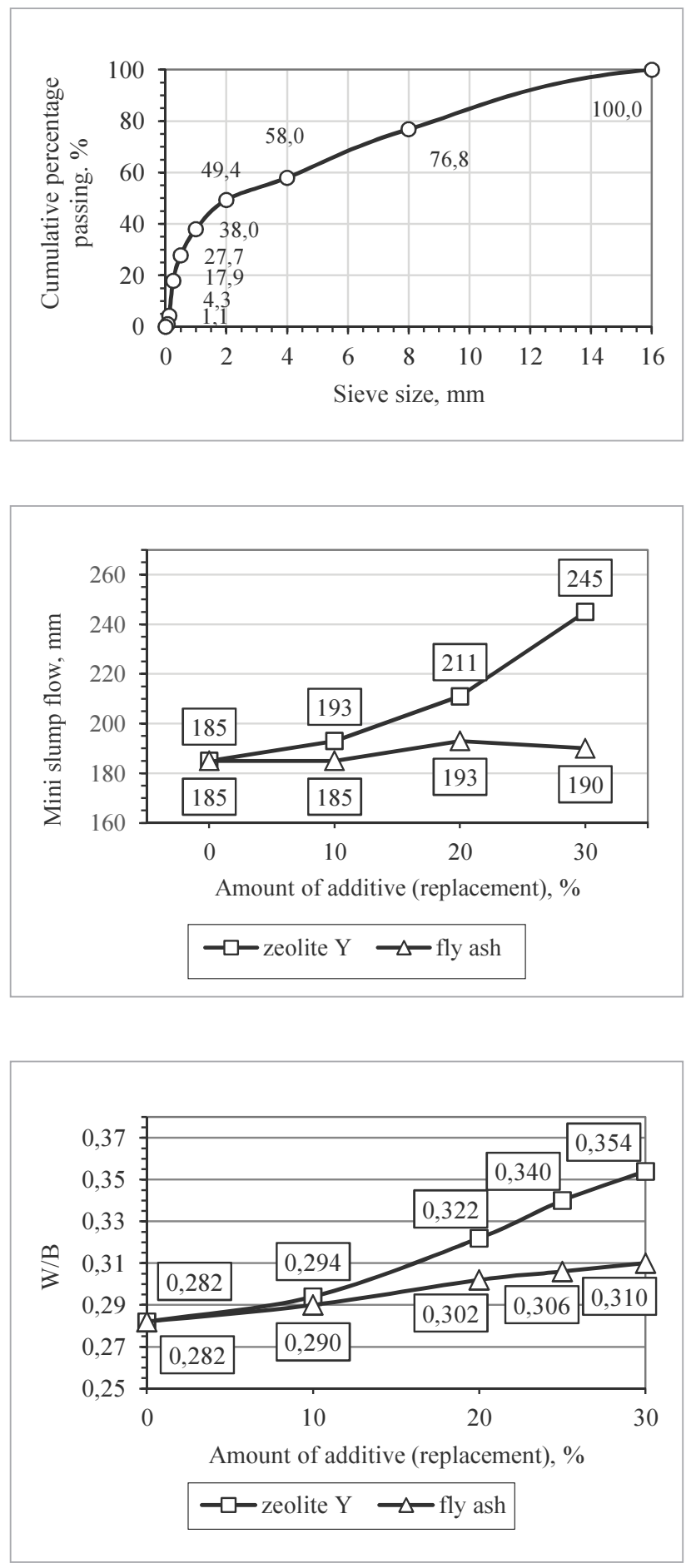

Fig. 1

Overall granulometric composition distribution of fine and coarse aggregates

Fig. 2

"Suttard" viscometer results for slump flow of mortars depending on the amount of selected additives

Fig. 3

Water demand of normal consistency depending on the amount of selected additives

The following fine aggregates were

used in concrete mixes: sand $0 / 2$ and $0 / 4$, and coarse aggregate - gravel of fraction $4 / 16$. In order to obtain a continuous curve of granulometric composition, containing higher amount of fine particles, the following comparative amounts of fillers were calculated using analytical and numerical methods according to their mass: sand $0 / 2-7.1 \%$, sand $0 / 4-47.3 \%$ and gravel $4 / 16-$ $45.6 \%$. Overall curve of granulometric composition of fillers is presented in Fig. 1. 
Fig. 4

SEM micrograph of zeolite Y particles

Table 2

Chemical composition and physical properties of fly ash, synthetic zeolite and Portland cement

Fig. 5

Laser granulometric composition of cement, zeolite and fly ash. Particle diameter histogram

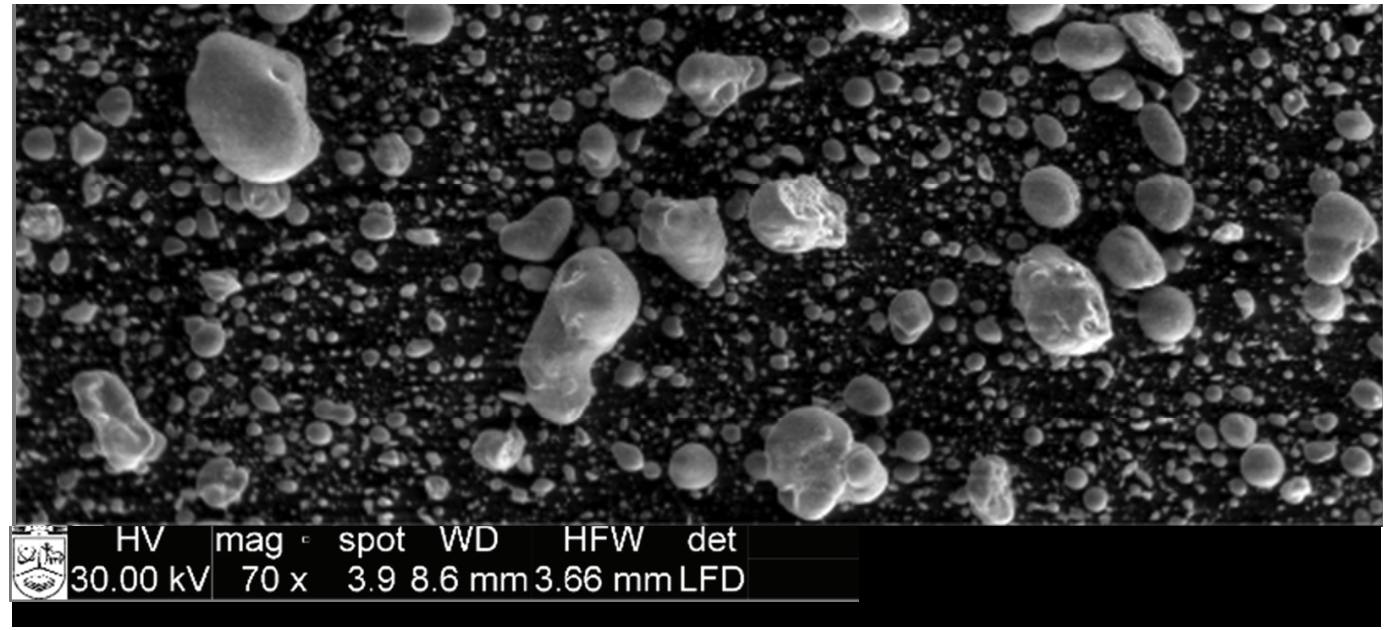

\begin{tabular}{c|c|c|c}
\hline $\begin{array}{c}\text { Chemical composition (\%) } \\
\text { and physical properties }\end{array}$ & Fly ash & $\begin{array}{c}\text { Zeolite } \\
\mathrm{Y}\end{array}$ & Cement \\
$\mathrm{CaO}$ & 2,44 & 0,5 & 62,1 \\
\hline $\mathrm{SiO}_{2}$ & 48,79 & 50,1 & 18,8 \\
\hline $\mathrm{Al}_{2} \mathrm{O}_{3}$ & 25,24 & 39,4 & 3,9 \\
\hline $\mathrm{Fe}_{2} \mathrm{O}_{3}$ & 5,30 & 1,3 & 2,8 \\
\hline $\mathrm{MgO}$ & 2,37 & 0,49 & 2,6 \\
\hline $\mathrm{Na}_{2} \mathrm{O}$ & 0,86 & 0,20 & 0,20 \\
\hline $\mathrm{K}_{2} \mathrm{O}$ & 3,56 & 0,07 & 1,06 \\
\hline $\begin{array}{c}\text { Specific gravity } \\
\text { Specific surface area } \\
\left(\mathrm{cm}^{2} / \mathrm{g}\right)\end{array}$ & 2110 & 2150 & 3150 \\
\hline
\end{tabular}

In this study, the commercially available Portland cement CEMII/A-LL 42,5R (specific surface $-460 \mathrm{~m}^{2} / \mathrm{kg}$; initial setting time - $160 \mathrm{~min}$, compression strength - 34.2 MPa (after 2 days) and 53.9 MPa (after 28 days)) was used. Commercially available fly ash from Polish coal-burning electrical power plant was used in this investigation, the physical, mechanical and chemical composition of which is presented in Table 2. Zeolitic waste was obtained from AB "Mažeikių nafta". It had been used as a catalyst in the process of oil refinery. Granulometric composition curves of cement, zeolitic waste, and fly ash are presented in Fig. 5, while SEM micrograph of zeolitic waste particles is presented in Fig. 4. Based on X-ray mapping, it is claimed that all peaks are attributed to zeolite $Y$ FCC is used in refineries to improve the yield of higher octane gasoline from crude oil during oil refining and cracking. When the catalytic properties of the FCC catalyst are degraded, the deactivated catalyst must be replaced with active (regenerated) or fresh catalyst. Spent FCC catalyst which, consists primarily of active silica $\left(\mathrm{SiO}_{2}\right)$ and alumina $\left(\mathrm{Al}_{2} \mathrm{O}_{3}\right)$, is considered as a waste material. In their scientific studies, many researchers indicate 
similar characteristics of zeolitic waste that they recorded, including the following: large specific surface area (Blaine value), porous surface structure, pozzolanic activity within hardened cement paste, higher WD ratio compared to cement, etc. Zeolitic waste column in Table 2 shows the chemical composition of the material (Aleknevičius 2008).

"Suttard" viscometer slump flow and water demand of normal consistency results of selected additives are also given in Fig. 2 and Fig. 3, respectively.

Steel fiber with standard hooked end geometrical shape was used. Fiber length $L=50 \mathrm{~mm}$, diameter $\mathrm{d}=1 \mathrm{~mm}$.

\section{X-ray diffraction}

The fractured pieces of hardened cement paste samples were crushed to pass through a $0.125 \mathrm{~mm}$ sieve and then immediately soaked in acetone for 5 days to stop the hydration of the cementitious materials. The samples were dried at $105^{\circ} \mathrm{C}$ in controlled oven for $48 \mathrm{~h}$. The dried samples were used for X-ray testing.
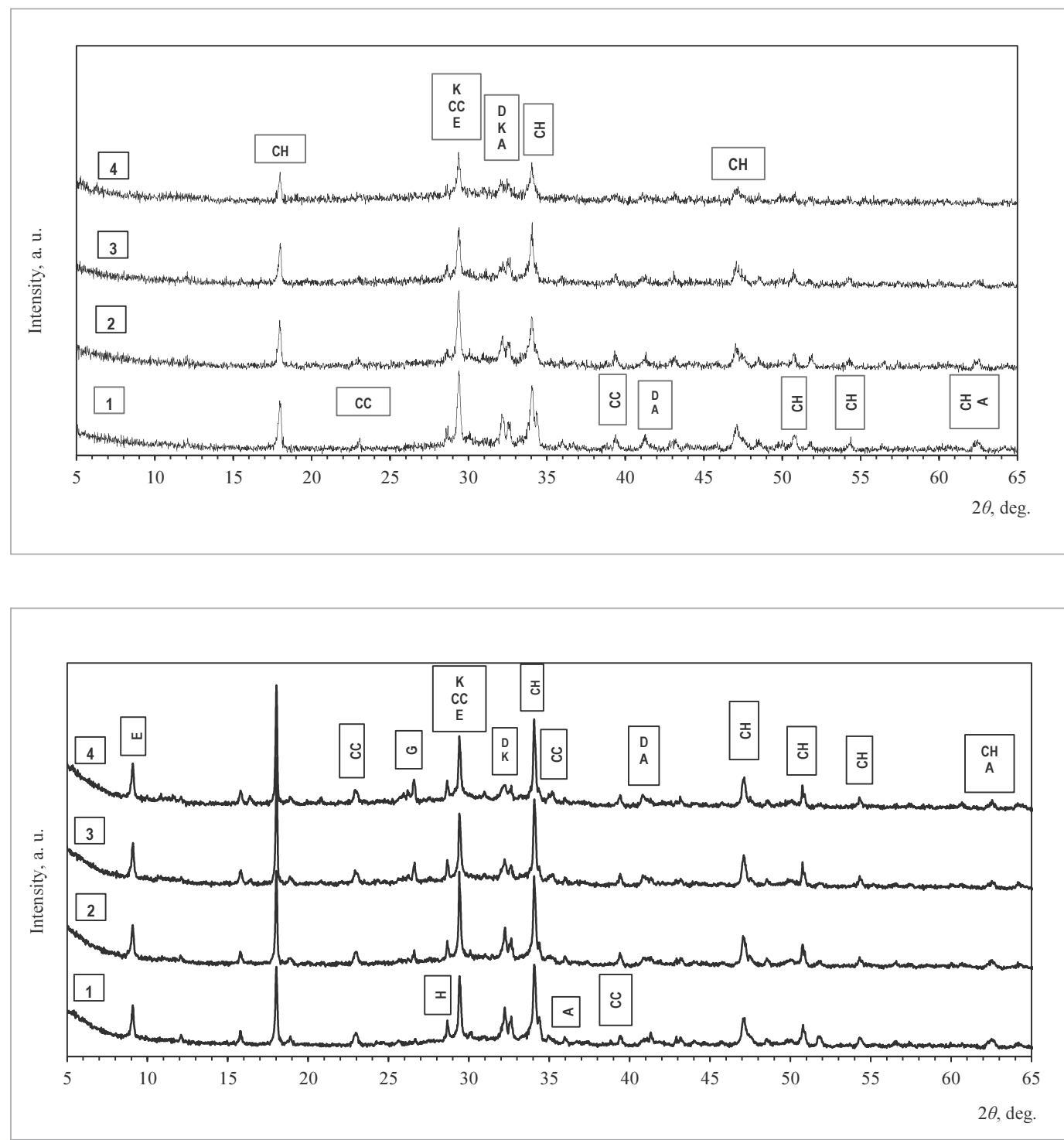

\section{Results and discussion}

Fig. 6

Selected range of the X-ray diffraction patterns of hardened cement paste after 28 days containing $0 \%(1), 10 \%$ (2), $20 \%$ (3), and $30 \%(4)$ of spent zeolitic catalytic cracking catalyst. The major peaks for each phase are labelled as follow: E - Ettringite; $\mathrm{CH}$ - Portlandite; CC - Calcite; G - Quartz; $\mathrm{K}$ - Calcium silicate hydrate; A - Alite; D - Belite

Fig. 7

Selected range of the $X$-ray diffraction patterns of hardened cement paste after 28 days containing 0\% (1), 10\% (2), 20\% (3), and $30 \%$ (4) of fly ash 
Fig. 8

Compressive strength of hardened cement paste partly replaced by additive. W/B ratio of water demand for paste of normal consistency was used

Fig. 9

Compressive strength (and change) of hardened cement paste partly replaced by additive after 90 days of curing when $\mathrm{W} / \mathrm{B}=$ const. $(0.350)$
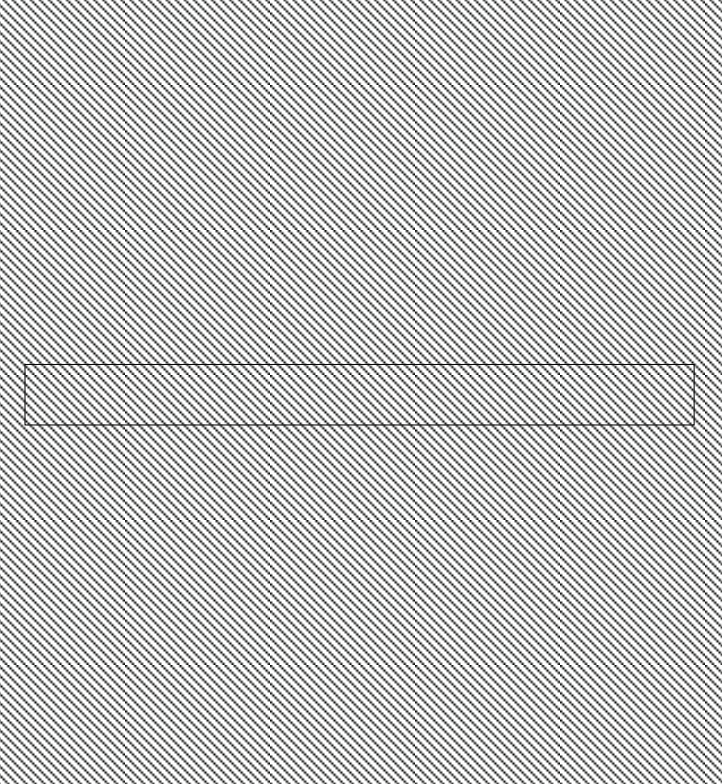

Amount of fly ash (replacement), \%

$$
\text { 戸28 days } \rightleftharpoons 90 \text { days } \triangle \text { =W/B }
$$

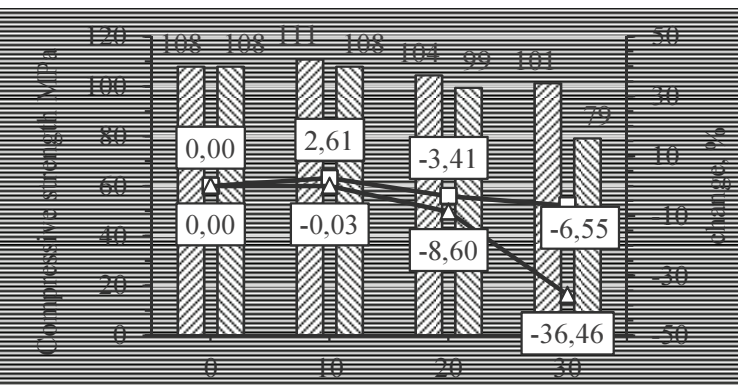

Amount of additive (replacement), \%

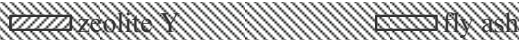

$\rightarrow \square$ change. Zeolite Y, \% $\rightarrow$ change. Fly ash, \%

\section{Fig. 10}

Shrinkage strain graph of samples prepared by means of partial replacement of cement by zeolitic waste material. Wet conditions

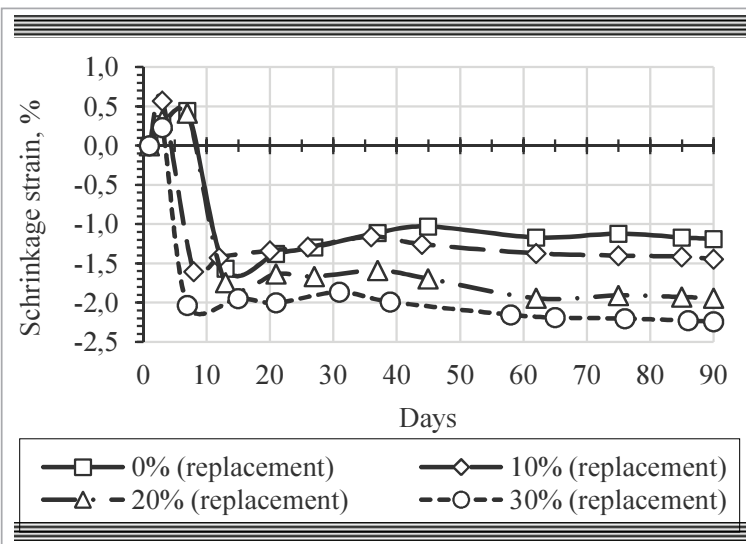

X-ray diffraction patterns of hardened cement paste specimens revealed that $\mathrm{Ca}(\mathrm{OH})_{2}$ decreased with the increase of zeolitic waste substitutes from 0 to $30 \%$ (Fig. 6). Comparing the four curves, the highest typical peak of $\mathrm{Ca}(\mathrm{OH})_{2}(0.493 \mathrm{~nm})$ is the most intense when the zeolitic waste is not used, i.e. in the control sample (Fig. 6, 1 curve.). Meanwhile, in the cement paste samples containing zeolitic waste, $\mathrm{Ca}(\mathrm{OH})_{2}$ typical peak decreases. Calcite peaks are less intensive when zeolite is used.

Fly ash substitution slightly modified the X-ray results with increased substitution from 0 to $30 \%$ (Fig. 7). Decrease level of the amount of portlandite with increasing fly ash replacement was noticeably lower than zeolitic waste samples or even undistinguishable. In this particular investigation, results show minimal pozzolanic activity of fly ash, which could be also proven in further parts of this paper.

The XRD analysis was performed on the D8 Advance diffractometer (Bruker AXS, Karlsruhe, Germany) operating at the tube voltage of $40 \mathrm{kV}$ and tube current of $40 \mathrm{~mA}$. The X-ray beam was filtered with $\mathrm{Ni} 0.02 \mathrm{~mm}$ filter to select the CuKa wavelength. Diffraction patterns were recorded in a Bragg-Brentano geometry using a fast counting detector "Bruker LynxEye" based on silicon strip technology. The specimens were scanned over the range $2 \theta=3-70^{\circ}$ at a scanning speed of $6^{\circ}$ min- 1 using a coupled two theta/ theta scan type.

\section{Compressive strength of hardened cement paste samples}

Compression test results of the cement paste samples after 28 and 90 days of curing are shown in Fig. 8 and Fig. 9. Results of samples where W/B (water/binder) ratio was set equal to 
water demand of normal consistency are presented in Fig. 8. W/B ratio of each sample is also plotted in $2 \mathrm{D}$ line graph in both figures. Upper graph shows samples with zeolitic waste replacement, while lower graph fly ash replacement. Compared to plain Portland cement paste $(0 \%$ replacement) at 28 and 90 days of curing, despite the higher W/B ratio, zeolite replacement increased the compressive strength of the concrete at replacement level of $10 \%$ (Fig. 8 upper). Increase of compressive strength when replacing part of cement by reactive zeolitic waste additive can be explained by pozzolanic reaction and denser granulometric composition of the mixture, as well as by the change in density. Although the density of synthetic zeolitic waste used in the research is by $\sim 34 \%$ lower than that of cement, when replacing $10 \%$ of cement by this additive, the highest compressive strength of hardened sample was obtained. After 28 and 90 days of curing, the compressive strength of samples with $20 \%$ zeolite replacement were almost the same as of the control pastes. The fly ash replacements in the pastes with a lower W/B appeared to contribute better to strength than that in the pastes with a higher W/B ratio. It has been already observed in research literature that there exists no certain effect of fly ash on compressive strength of SCC mixes (Sabet et al. 2013). No increase in compressive strength with higher replacements of fly ash was observed in this research.

In contrast to the compressive strength of samples with incorporation of zeolitic waste and fly ash, Fig. 9 shows second compressive test results of samples with constant 0.350 W/B ratio carried out after 90 days. Relative percentage change in compressive strength is plotted for both additives. Comparing the cement pastes with blended in zeolitic waste and fly ash, three observations could be noted: a) replacement of cement by zeolitic waste resulted in less compressive strength reduction in all ages; 2 ) natural zeolite replacement shows better compressive strength results despite higher water content in test where $\mathrm{W} / \mathrm{B}$ = water demand of normal consistency; 3 ) similar to natural zeolite, fluid zeolitic catalytic cracking (FCC) catalyst shows clear increase in compressive
Fig. 11

Shrinkage strain graph of samples prepared by means of partial replacement of cement by fly ash. Wet conditions

Fig. 12

Upper: Dependency of the slump flow of the mixture on the amount of added steel fiber. Lower: Dependency of the concrete mix density on the amount of steel fiber and used additive 
Fig. 13

Upper: Dependency of slump flow of the nonfiber mixture on the type and amount of additive and superplasticizer.

Lower: $25 \mathrm{~kg} / \mathrm{m}^{3}$ of steel fiber incorporation in the mix strength at replacement level of $10 \%$. These observations indicate higher pozzolanic activity of the zeolitic waste and significant differences from that of fly ash.

\section{Shrinkage strain of hardened cement paste}

The effect of zeolitic additives as a supplementary cementitious material on drying shrinkage of concrete has not been deeply investigated. In this study, identical hardened cement paste prism specimens, $40 \times 40 \times 160 \mathrm{~mm}$ in size, were cast and the deformation during 90 days was measured in wet conditions. W/B ratio $=0.322$ was chosen. Three samples for each mixture were prepared and average percentage of deformation values were calculated in every measurement. Measurements were recorded starting with $24 \mathrm{~h}$ after casting, right after demold. It should be noted that after the initial, and during later measurements, all the prisms were stored in one water tank with a temperature of $20-22^{\circ} \mathrm{C}$. Fig. 10 and Fig. 11 present the drying shrinkage of samples with zeolitic waste material and fly ash, respectively, during selected period of curing days in wet conditions. According to those figures, generally, the application of fly ash led to a slightly lower drying shrinkage compared to zeolitic waste. However, in both cases, 10\%, 20\% and 30\% of the cement replacement by selected additives influenced higher shrinkage strain respectively. Particularly after $~ 15$ days of curing. Najimi et al. (2012) hypothesize an idea that zeolite as a porous material absorbs a part of water in fresh state of concrete, and this water gradually migrates out

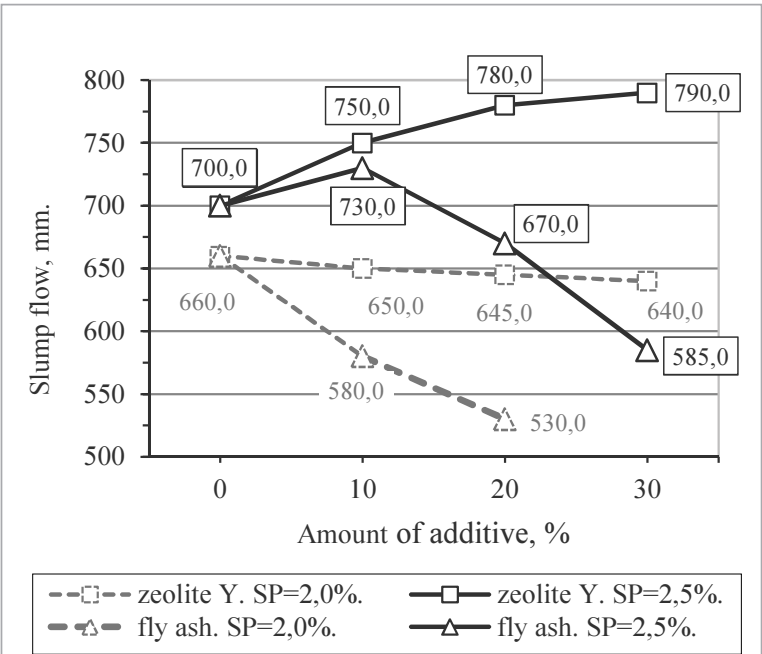
of natural zeolite during drying. Wet conditions eliminate the moisture evaporation component, uneven and non-linear water evaporation rate.

\section{Investigation of concrete properties}

For each mixture, a total volume of 22 L. of concrete was prepared in a pan planetary-type mixer. Immediately after the mixing procedure, the slump flow test was performed. Each slump flow test procedure was filmed and then slump flow $t_{500}$ was determined by using computational video editing software.

Investigation of the technological properties of mixtures was started with experimental mixture without zeolitic waste (mix A). With those mixtures, attempts to identify the influence of steel fiber on slump flow of the mixture were made employing the Abhram's cone method and the J-ring method.

According to the slump flow test results, all mixes produced with blended cements met the EN 206-9 specified SCC requirements. The visual stability index (VSI) values of mixes 
were between zero (no evidence of segregation or bleeding) and one (no evidence of segregation and slight bleeding observed as a sheen on the concrete mass) in accordance with ASTM C611. Since the water, aggregates, and chemical admixture content were constant, the impact of zeolitic waste and fly ash replacement and amount of steel fiber on flowability, density, slump flow time $t_{500}$, and J-ring test results were recorded.

Stability of each mixture was tested by the three-cylinder method in order to investigate the stability and segregation of concrete mixture. Slump flow of the mixture dependency on the amount of steel fiber is presented in Fig. 12 (upper) which shows that steel fiber decreases the slump flow of both mixtures.

In many cases discussed in section 1 of this paper, the use of natural and synthetic zeolite decreased the workability of concrete which was compensated by using a higher amount of superplasticizer or VMA. The higher demand of superplasticizer in the concrete mixtures incorporating zeolite can be attributed to the porous and platy microstructure of zeolite (Najimi et al. 2012).

When using $2.0 \%$ of superplasticizer, slight decrease of slump flow of the mixture was observed, while in those mixtures including $2.5 \%$ of added plasticizer and increasingly higher amount of cement replaced by zeolitic waste, significant slump flow increase of the mixture was observed (Fig. 13 upper and Fig. 15 upper). Yet, in both cases, when increasing the amount of zeolitic waste, the mixture tended to become "slower" and more viscous. The mixture including zeolitic waste would stop flowing on the measuring table in significantly greater time. This

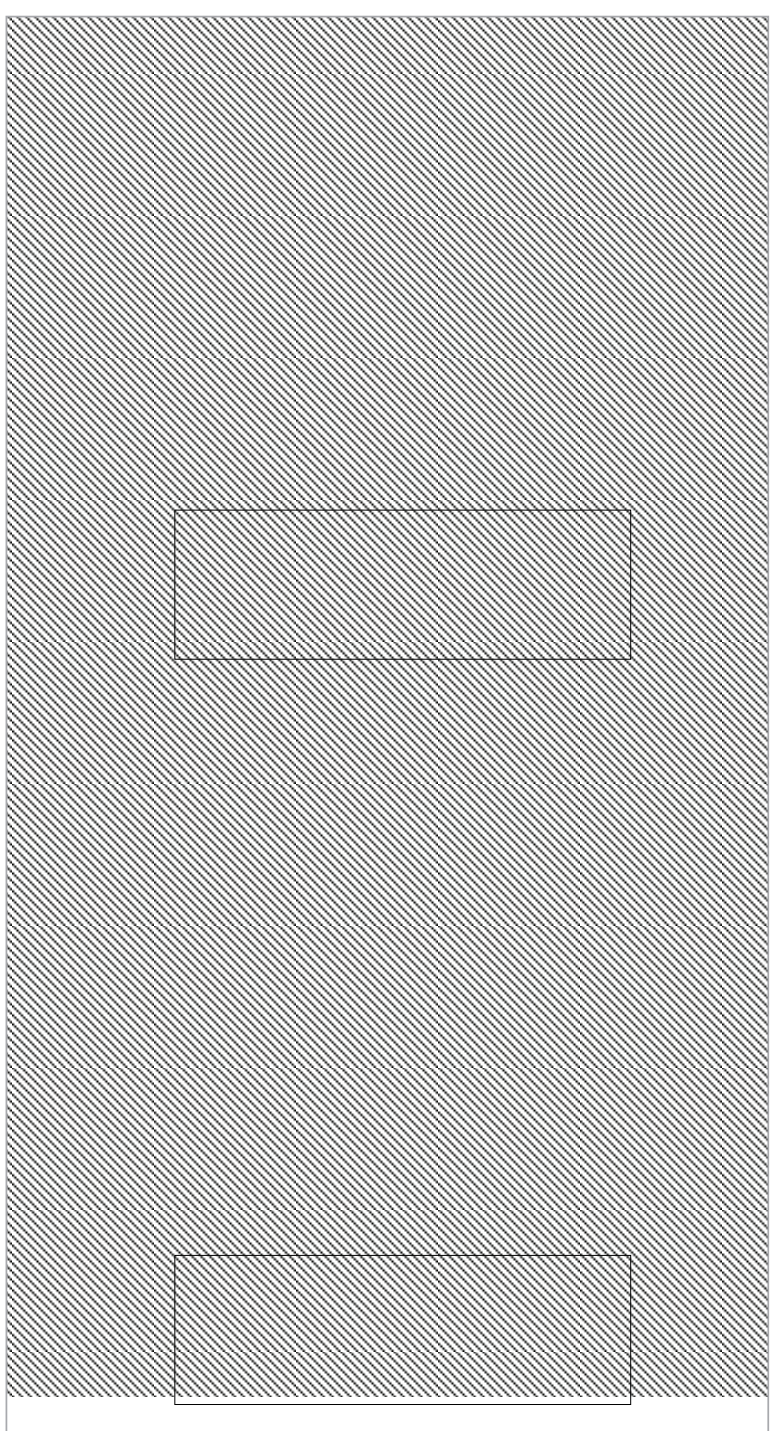

Fig. 14

Upper: Dependency of concrete mix density on the type, amount of additive (replacement) and incorporation of steel fiber. Lower: Dependency of slump flow on the type, amount of additive (replacement) and incorporation of steel fiber

\begin{tabular}{|c|c|c|c|c|}
\hline 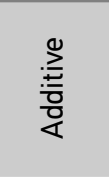 & $\begin{array}{c}\text { Replace- } \\
\text { ment } \\
\text { level, \% }\end{array}$ & $\begin{array}{c}\text { Cement } \\
\mathrm{kg} / \mathrm{m}^{3}\end{array}$ & $\begin{array}{l}\text { Compres- } \\
\text { sive } \\
\text { strength, } \\
\mathrm{MPa}\end{array}$ & $\begin{array}{l}\text { Compres- } \\
\text { sive strength } \\
\text { / cement } \\
\text { content ratio }\end{array}$ \\
\hline - & $\begin{array}{c}0 \\
\text { (control) }\end{array}$ & 410 & 60,0 & 0,146 \\
\hline \multirow{3}{*}{$\begin{array}{l}\text { Zeolitic } \\
\text { waste }\end{array}$} & 10 & 369 & 51,5 & 0,140 \\
\hline & 20 & 328 & 50,8 & 0,155 \\
\hline & 30 & 287 & 53,3 & 0,186 \\
\hline \multirow{3}{*}{ Fly ash } & 10 & 369 & 52,5 & 0,142 \\
\hline & 20 & 328 & 56,6 & 0,173 \\
\hline & 30 & 287 & 49,3 & 0,172 \\
\hline
\end{tabular}

Table 3

Comparison of compressive strength / cement content ratio of the samples 
Fig. 15

Upper: Dependency of slump flow and J-ring slump flow on the amount of additive (replacement). Content of steel fiber -

$25 \mathrm{~kg} / \mathrm{m}^{3}$. Lower: the flow time $t 500$ on amount of additive and steel fiber content

Fig. 16

Upper: compressive strength of hardened concrete samples with cement partly replaced by zeolite. Lower: samples with cement partly replaced by fly ash

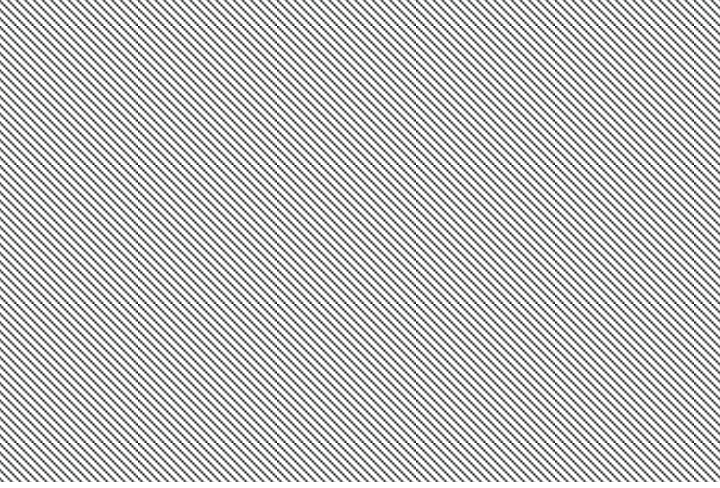

-—— zeolite Y. Slump flow - i - zeolite Y. J-ring slump flow $\longrightarrow-$ fly ash. Slump flow

- ¿ - fly ash. J-ring slump flow

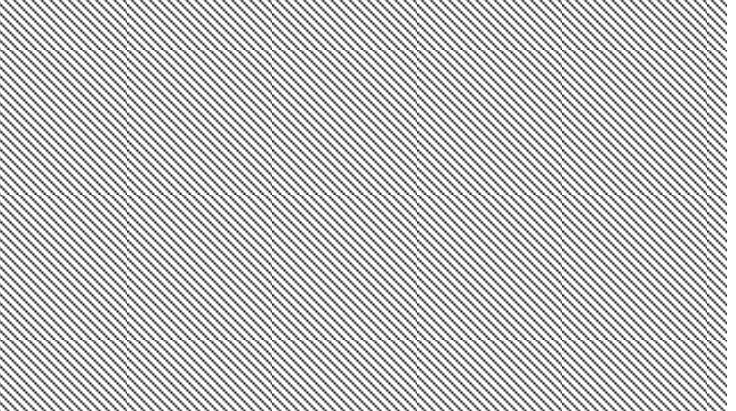

- - - - zeolite Y. Steel fiber - $0 \mathrm{~kg} . / \mathrm{m} 3$

$-\square-z e o l i t e ~ Y$. Steel fiber - $25 \mathrm{~kg} . / \mathrm{m} 3$

- - - - - fly ash. Steel fiber - $0 \mathrm{~kg} . / \mathrm{m} 3$ $\triangle$ fly ash. Steel fiber - $25 \mathrm{~kg} . / \mathrm{m} 3$

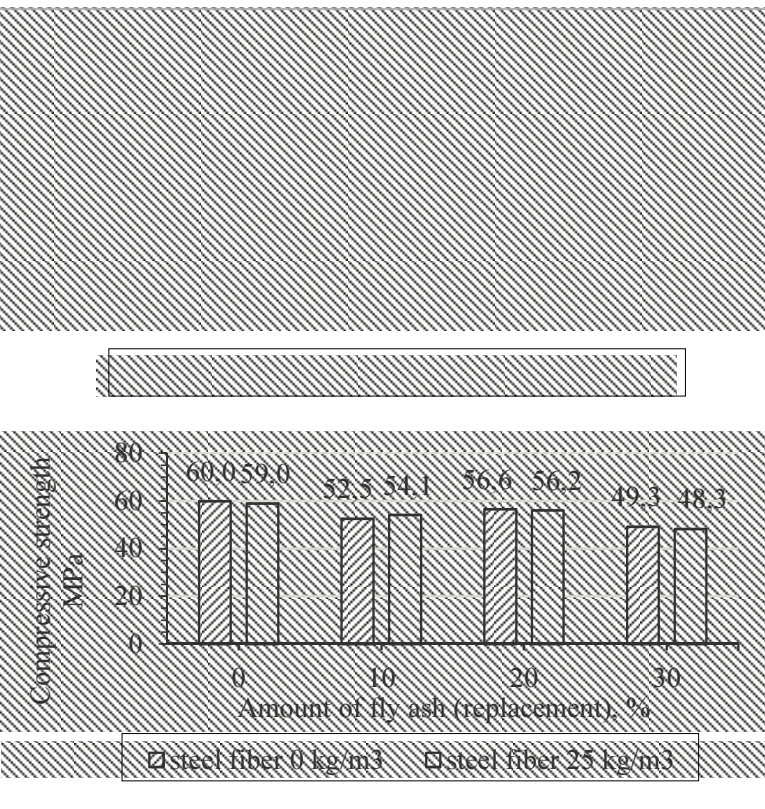

fact is also supported by significantly increasing flow time of the mixture.

Quite different results of rheology properties with fly ash replacement were observed. 10\% replacement by fly ash translated into higher slump flow $(730 \mathrm{~mm})$, compared to control mix (700), while higher replacement resulted in intense decrease of slump flow (Fig. 13 upper and Fig. 15 upper). However, the tendency of "slower" and more viscous mix remains similar to that of zeolitic waste (Fig. 15 lower).

The third phase of the investigation (mix $\mathrm{C}$ and mix $\mathrm{F}$ ) was intended for investigating the complex effect of zeolitic waste and steel fiber on technological properties of SCC mixture. In this case, steel fiber amount of $25 \mathrm{~kg} / \mathrm{m}^{3}$ was chosen, and mixtures containing 10\%, 20\%, and $30 \%$ of cement replacement by selected waste material were produced. Complex effect of zeolitic waste and steel fiber on slump flow of the mixture was negative (Fig 13 lower and Fig. 14 lower). Zeolitic waste and fly ash showed an insignificant decreasing effect on concrete density, which can be attributed to their lower specific gravity in comparison with that of cement $\left(3150 \mathrm{~kg} / \mathrm{m}^{3}\right)$ (Fig. 12 lower and Fig. 14 upper).

\section{Compressive strength of concrete samples}

The results of compressive strength of SCC and SCFRC mixtures made with various contents of zeolitic waste and fly ash additives are included in Fig. 16 and Fig. 17. The upper and lower bar graphs in Fig. 16 show the compressive strength values after 90 days of curing when different replacement levels of selected additives with or without the incorporation of steel fiber were used. No expected increase of compressive 
strength value at level of 10\% replacement by zeolitic waste was observed. Generally, both additives exhibit lower compressive strength values in comparison to the control mixture ( $0 \%$ replacement). However, no gradual decrease of compressive strength was observed when replacement ratio was increased from 0 to $30 \%$. Fig. 17 presents comparative compressive strength results and percentage change without and with the incorporation of steel fiber, respectively, with both additives. In this case, the loss in compressive strength of samples with zeolitic waste and fly ash was $12.5 \%$ and $21.8 \%$ respectively (see Fig. 17). Compressive strength / cement content ratio also shows clear pozzolanic activity (see Table 3 ).

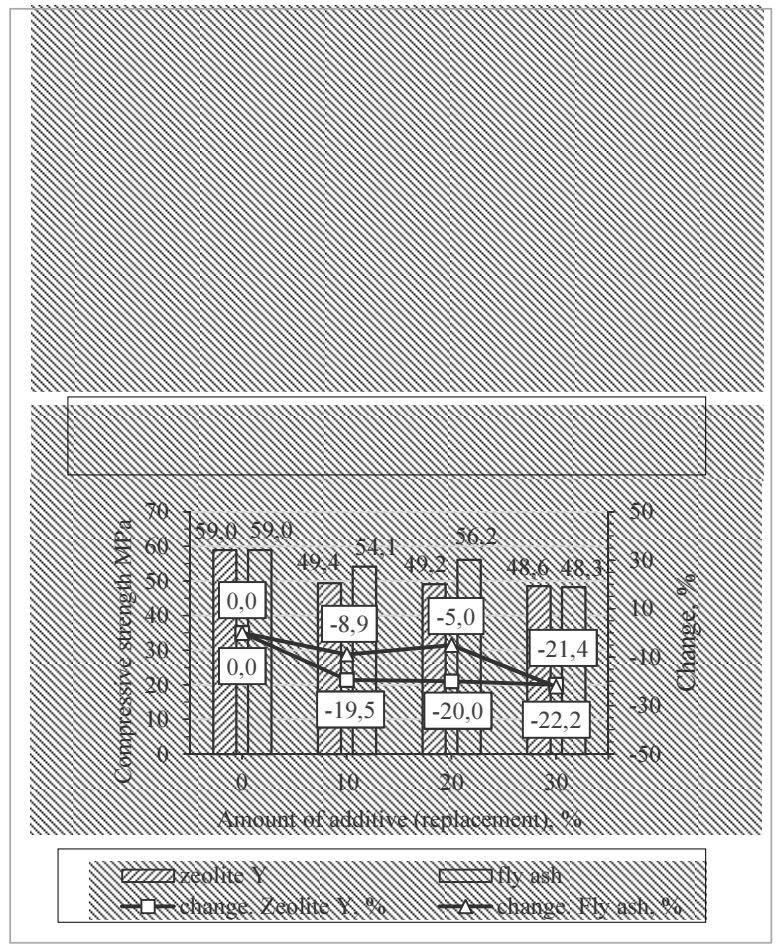

In this investigation, fly ash additive is characterized by finer particles compared to spent zeolitic catalytic cracking catalyst. However, despite contamination during the process of oil cracking and due to its porous structure, replacing cement by $30 \%$ of zeolitic waste, water demand in standard consistency paste increased by $20.3 \%$, while in case of fly ash $-9.0 \%$. Despite that, mini cone slump flow of mortar test revealed better zeolitic waste flowability results, while fly ash did not show any significant increase under the same conditions.

Cement replacement by zeolitic waste and fly ash alters the rheological properties of the concrete quite differently. It was observed that when the amount of superplasticizer in the mixture was $2.0 \%$, the slump flow of the mixtures was decreasing with increasing replacement level of fly ash and zeolitic waste additives, while when the amount of superplasticizer was $2.5 \%$, an increase of slump flow of the zeolitic waste mixture was registered. Slump flow values of the concrete without zeolitic waste additive $700 \mathrm{~mm}$, and with $30 \%$ of additive $-790 \mathrm{~mm}$ were observed. Contrary to zeolitic waste, fly ash showed decreasing slump flow results with an exception at replacement level of $10 \%$. Slump flow time $t_{500}$ was observed to be higher with increasing of both selected additives. Zeolitic waste exhibits slightly greater slump flow time $t_{500}$ propagation compared to fly ash. Zeolitic waste and fly ash increased $t_{500}$ ratio from 1.16 to 3.72 and $3.22 \mathrm{sec}$. in non-fibered mixtures, respectively. It was also found that zeolitic waste and fly ash, together with incorporation of steel fiber, increase in slump flow time at similar manner. The complex effect of selected additives and steel fiber on the slump flow of the mixtures was found to be different according to the additive. Together zeolitic waste and steel fiber $\left(25 \mathrm{~kg} / \mathrm{m}^{3}\right)$ showed linear decrease in slump flow, while fly ash increased slump flow at replacement levels of $10 \%$ and $20 \%$.

Examination of compressive strength of hardened cement paste where W/B ratio was equal to water demand of normal consistency after 28 days of curing showed that replacing $10 \%$ of cement by zeolitic waste resulted in an increase of strength of $12.9 \%$ on average, while fly ash additive did not show any positive change neither in 28 day, nor in 90 day compressive strength. 20\% replacement of zeolitic waste showed comparable compressive strength results to control mix.
Fig. 17

Upper: compressive strength of hardened non fiber concrete samples with cement partly replaced by additive. Lower: plus steel fiber $25 \mathrm{~kg} / \mathrm{m}^{3}$ 
When determining the compressive strength of the hardened cement paste samples after 90 days of curing, where W/B=const. (0.354), zeolitic waste also showed better results and probably higher pozzolanic activity. Minor compressive strength losses were observed at replacement levels of 20\% and 30\%: $-3,41$ and $-6,55 \%$ respectively, while fly ash additive $-8,60$ and $-36,46 \%$. Lower fly ash pozzolanic activity in comparison to zeolitic waste could also be proven by XRD investigation given in this paper. Decrease level of the amount of portlandite, alite, and belite with increasing fly ash replacement was noticeably lower than zeolitic waste samples or even undistinguishable.

Shrinkage strain test in wet conditions was performed in this investigation eliminating the water evaporation component from the contraction process. Probably, due to lower pozzolanic activity of fly ash blended pastes also discovered by other test in this paper, shrinkage strain was found to be lower when using the fly ash additive.

Zeolitic waste and fly ash additives exhibit lower compressive strength values of the concrete samples in comparison to control mixture ( $0 \%$ replacement.). No expected increase of compressive strength value at level of $10 \%$ replacement of zeolitic waste was observed. However, no gradual decrease of compressive strength was found when using both additives when replacement level increased from $0 \%$ to $30 \%$. On the contrary to mortar samples, fly ash exhibited lower relative decrease in compressive strength at tested replacement levels in samples with and without the incorporation of fiber. Besides, the highest compressive strength / cement content ratio was found to be with zeolitic waste, $30 \%$ replacement sample.

Collectively, in terms of rheology properties, spent catalytic cracking catalyst additive was found to be more attractive. Its ability to change the viscosity of mixture, with minimal interference to final slump flow together with increased compressive strength in comparison to fly ash additive, should receive more attention from academic and manufacture aspects.

Acknow-

This work has been supported by the European Social Fund within the project "Development and application of innovative research methods and solutions for traffic structures, vehicles and their ledgment flows", project code VP1-3.1-ŠMM-08-K-01-020.

\section{References}

Abd Elrahman M, B Hillemeier. 2014. Combined Effect of Fine Fly Ash and Packing Density on the Properties of High Performance Concrete: An Experimental Approach. In: Construction and Building Materials, Elsevier Ltd, 58, 225-233.

Ahmadi B, M Shekarchi. 2010. Use of Natural Zeolite as a Supplementary Cementitious Material. In: Cement and Concrete Composites, Elsevier Ltd, 32(2), 134-141.

Aleknevičius M. 2008. Research on Petrochemical Industry Catalyst Waste. In: 11-0ji Lietuvos Jaunuju Mokslininkų Konferencija „Mokslas - Lietuvos Ateitis“ [11th Conference of Lithuania Young Researchers "Science - Feature of Lithuania"], Vilnius, 11-19.

Bilim C. 2011. Properties of Cement Mortars Containing Clinoptilolite as a Supplementary Cementitious Material. In: Construction and Building Materials, Elsevier Ltd, 25(8), 3175-3180.

Bukowska M, B Pacewska, I Wilińska. 2004. Influence of Spent Catalyst Used for Catalytic Cracking in a
Fluidized Bed on Sulphate Corrosion of Cement Mortars: I. Na2SO4 Medium. In: Cement and Concrete Research, 34(5), 759-767. http://dx.doi. org/10.1016/j.cemconres.2003.08.007

Caputo D, B Liguori, C Colella. 2008. Some Advances in Understanding the Pozzolanic Activity of Zeolites: The Effect of Zeolite Structure. In: Cement and Concrete Composites, 30(5), 455-462. http://dx.doi. org/10.1016/j.cemconcomp.2007.08.004

Chan S, X Ji. 1999. Comparative Study of the Initial Surface Absorption and Chloride Diffusion of High Performance Zeolite, Silica Fume and PFA Concretes. In: Cement and Concrete Composites, 21, 1-8. http:// dx.doi.org/10.1016/S0958-9465(99)00010-4

Chen H-L, Y-S Tseng, K-C Hsu. 2004. Spent FCC Catalyst as a Pozzolanic Material for HighPerformance Mortars. In: Cement and Concrete Composites, 26(6), 657-664. http://dx.doi. org/10.1016/S0958-9465(03)00048-9 
Dinakar P, M Kartik Reddy, M Sharma. 2013. Behaviour of Self Compacting Concrete Using Portland Pozzolana Cement with Different Levels of Fly Ash. In: Materials \& Design, Elsevier Ltd, 46, 609-616.

Glasser FP et al. 2011. Pozzolanic Activity of a Spent Fluid Catalytic Cracking Catalyst Residue. In: Advances in Cement Research, 23(3), 105-111. http://dx.doi.org/10.1680/adcr.9.00036

Karakurt C, IB Topçu. 2011. Effect of Blended Cements Produced with Natural Zeolite and Industrial by-Products on Alkali-Silica Reaction and Sulfate Resistance of Concrete. In: Construction and Building Materials, 25(4), 1789-1795. http://dx.doi. org/10.1016/j.conbuildmat.2010.11.087

Najimi M, J Sobhani, B Ahmadi, M Shekarchi. 2012. An Experimental Study on Durability Properties of Concrete Containing Zeolite as a Highly Reactive Natural Pozzolan. In: Construction and Building Materials, Elsevier Ltd, 35, 1023-1033.

Pacewska B, M Bukowska, I Wilińska, M Swat. 2002. Modification of the Properties of Concrete by a New Pozzolan-a Waste Catalyst from the Catalytic Process in a Fluidized Bed. In: Cement and Concrete Research, 32, 145-152. http://dx.doi.org/10.1016/ S0008-8846(01)00646-9

Pacewska B, M Nowacka, M Aleknevičius, V Antonovič. 2013. Early Hydration of Calcium Aluminate Cement Blended with Spent FCC Catalyst at Two Temperatures. In: Procedia Engineering, Elsevier B.V., 57, 844-850.

Payá J, J Monzó, M Borrachero. 2001. Physical, Chemical and Mechanical Properties of Fluid Catalytic Cracking Catalyst Residue (FC3R) Blended Cements. In: Cement and Concrete Research, 31, 1-5. http:// dx.doi.org/10.1016/S0008-8846(00)00432-4

Payá J, J Monzó, M Borrachero, P Garcés. 2009. Outstanding Aspects on the Use of Spent FCC Catalyst in Binders. In: 1st Spanish National Conference on Advances in Materials Recycling and Eco - Energy, Madrid, 12-13.
Ponikiewski T. 2010. The Workability of Steel Fibre Reinforced Self-Compacting Concrete. In: The 10th International Conference "Modern Buildind Materials, Structures and Techniques," Vilnius, Vilnius Gediminas Technical University, 264-269.

Poon C, L Lam, S Kou, Z Lin. 1999. A Study on the Hydration Rate of Natural Zeolite Blended Cement Pastes. In: Construction and Building Materials, 13(8), 427-432. http://dx.doi.org/10.1016/S09500618(99)00048-3

Prisco M di, F Liberato. 2011. Concrete and Construction Technology - the Fibre Reinforced Concrete Experience. In: Fib Symposium Prague 2011, Prague, 253-268.

Ranjbar MM, R Madandoust, SY Mousavi, S Yosefi. 2013. Effects of Natural Zeolite on the Fresh and Hardened Properties of Self-Compacted Concrete. In: Construction and Building Materials, Elsevier Ltd, 47, 806-813.

Sabet FA, NA Libre, M Shekarchi. 2013. Mechanical and Durability Properties of Self Consolidating High Performance Concrete Incorporating Natural Zeolite, Silica Fume and Fly Ash. In: Construction and Building Materials, Elsevier Ltd, 44, 175-184.

Şahmaran M et al. 2008. Evaluation of Natural Zeolite as a Viscosity-Modifying Agent for Cement-Based Grouts. In: Cement and Concrete Research, 38(7), 930-937. http://dx.doi.org/10.1016/j.cemconres.2008.03.007

Su N, H-Y Fang, Z-H Chen, F-S Liu. 2000. Reuse of Waste Catalysts from Petrochemical Industries for Cement Substitution. In: Cement and Concrete Research, 30(11), 1773-1783. http://dx.doi. org/10.1016/S0008-8846(00)00401-4

Wu J-H, W-L Wu, K-C Hsu. 2003. The Effect of Waste Oil-Cracking Catalyst on the Compressive Strength of Cement Pastes and Mortars. In: Cement and Concrete Research, 33(2), 245-253. http://dx.doi.org/10.1016/ S0008-8846(02)01006-2

\section{PAULIUS GRIGALIŪNAS}

Ph.D. student

Kaunas University of Technology, The Faculty of Civil Engineering and Architecture

\section{Main research area}

Self-compacting fiber reinforced concrete, fiber orientation factor, rheology properties of concrete

\section{Address}

Studentu st. 48, LT-51367 Kaunas, Lithuania

Tel. +37067415509

E-mail: paulius.grigaliunas@ktu.lt

\section{ŽYMANTAS RUDŽIONIS}

Assoc. Professor

Kaunas University of Technology, The Faculty of

Civil Engineering and Architecture

Main research area

Self-compacting concrete, decorative concrete

\section{Address}

Studentu st. 48, LT-51367 Kaunas, Lithuania

+370687 750991

zymantas.rudzionis@ktu.lt

\section{About the authors}

